\title{
Effects of Grain Boundary Precipitation on Creep Rupture Properties of Alloys 706 and 718 Turbine Disk Forgings
}

\author{
T. Takahashi, T. Ishiguro, K. Orita, J. Taira, T. Shibata and S. Nakata \\ The Japan Steel Works, Ltd. \\ 4 Chatsu-machi, Muroran, Hokkaido 051, Japan
}

\begin{abstract}
Creep rupture strength and ductility of Alloys 706 and 718 turbine disk forgings were investigated in relation to the effect of grain boundary precipitation introduced by an intentional stabilizing treatment in the temperature range of 780 to $900{ }^{\circ} \mathrm{C}$. After the two step age hardening treatment at 720 and $620^{\circ} \mathrm{C}$, creep strain curves to rupture were continuously measured at test temperatures of $600^{\circ} \mathrm{C}$. Significant improvements of the rupture life and ductility were found in the wavy grain boundary microstructures of stabilized alloy 706 with necdle shaped and cellular precipitations of $\eta$ phase. These precipitates appear to originate at a grain boundary and to grow in specific intragrain directions, which result in wavy shapes of grain boundary. In contrast with this, straight grain boundaries with globular and plate-like precipitate were observed in the stabilized alloy 718, which always caused the decreasing of creep rate and rupture life. It may be concluded that the beneficial effect of stabilizing treatment for alloy 706 is attributed to the wavy grain boundary formation and the dispersions of creep strain at these wavy boundaries.
\end{abstract}

\section{Introduction}

$\mathrm{Ni}$ - Fe base superalloys 706 and 718, which are age-hardened by combined precipitation of fine $\gamma^{\prime}$ and $\gamma$ " in austenitic structure, have been widely used for higher temperature services such as gas turbine disks ${ }^{1,-51}$. For Alloy 706, a stabilizing heat treatment is proposed to improve the creep rupture life, which is performed to produced grain boundary precipitation between solution annealing and age-hardening heat treatments ${ }^{6)-9)}$. In order to understand the effect of the stabilizing heat treatment on tensile and creep rupture properties of Alloy 706, metallurgical and mechanical examinations were carried out in relation to the effect of grain boundary precipitation. In this study, morphology of the precipitates and shape of the grain boundary of Alloys 706 and 718 were intentionally varied by changing the stabilizing temperature between 780 and $900^{\circ} \mathrm{C}$. And, results obtained in short-term tensile and creep tests for Alloys 706 and 718 were compared based on metallurgical points of view. Significant improvements of rupture life and ductility were

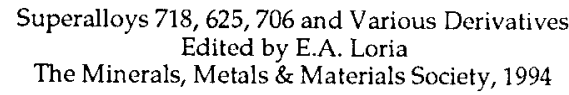


found in wavy grain boundary microstructures of stabilized Alloy 706 with needle shaped and cellular precipitates of $\eta$ phase.

\section{Materials and Experimental Procedure}

Chemical composition of alloys 706 and 718 used for this study is listed in Table 1. The materials were taken from the gas turbine disk forgings which were manufactured by vacuum induction melting (VIM) and electro-slag-remelting (ESR), and then after diffusion heat treatment for homogenization of the ESR ingots subjected to forging practice using 10,000 ton hydraulic press. Heat treatment conditions for these materials are shown in Figure 1. Stabilizing heat treatment for Alloy 706 is usually performed by re-heating to the stabilizing temperature after solution anneal ing. In this study, stabilizing treatment is performed continuously after solution treatment without any cooling down process from the point of view of industrial advantage. In order to examine the effect of grain boundary precipitation on the creep properties of both alloys, stabilizing temperatures are intentionally varied in the range of 790 to $980^{\circ} \mathrm{C}$. The Alloys 706 and 718 with various morphology of grain boundary precipitation were subjected to short time tensile and creep tests. And, microstructural evaluations were carried out by means of optical microscopy, scanning electron microscopy (SEM) and transmission electron microscopy (TEM).

Table I Chemical compositions of Alloys 706 and 718 (mass \%)

\begin{tabular}{|c|c|c|c|c|c|c|c|c|c|c|c|c|c|c|c|c|c|}
\hline & & $\mathrm{C}$ & $\mathrm{Si}$ & $\mathrm{Mn}$ & $\mathrm{P}$ & $\mathrm{S}$ & $\mathrm{Ni}$ & $\mathrm{Cr}$ & $\mathrm{Cu}$ & Mo & $\mathrm{Al}$ & $\mathrm{Ti}$ & $\mathrm{Nb}$ & $\mathrm{Mg}$ & B & $\mathrm{Fe}$ & $\mathrm{N}$ \\
\hline Alloy & 706 & .008 & .05 & .02 & $<.003$ & $<.0005$ & 42.00 & 15.65 & .01 & - & .26 & 1.54 & 2.96 & .0010 & .0034 & 37.10 & .0046 \\
\hline Alloy & 718 & .029 & .05 & .01 & $<.003$ & .0010 & 51.23 & 18.11 & .05 & 2.84 & .55 & 1.01 & 5.00 & .0030 & .0050 & 20.88 & .0105 \\
\hline
\end{tabular}

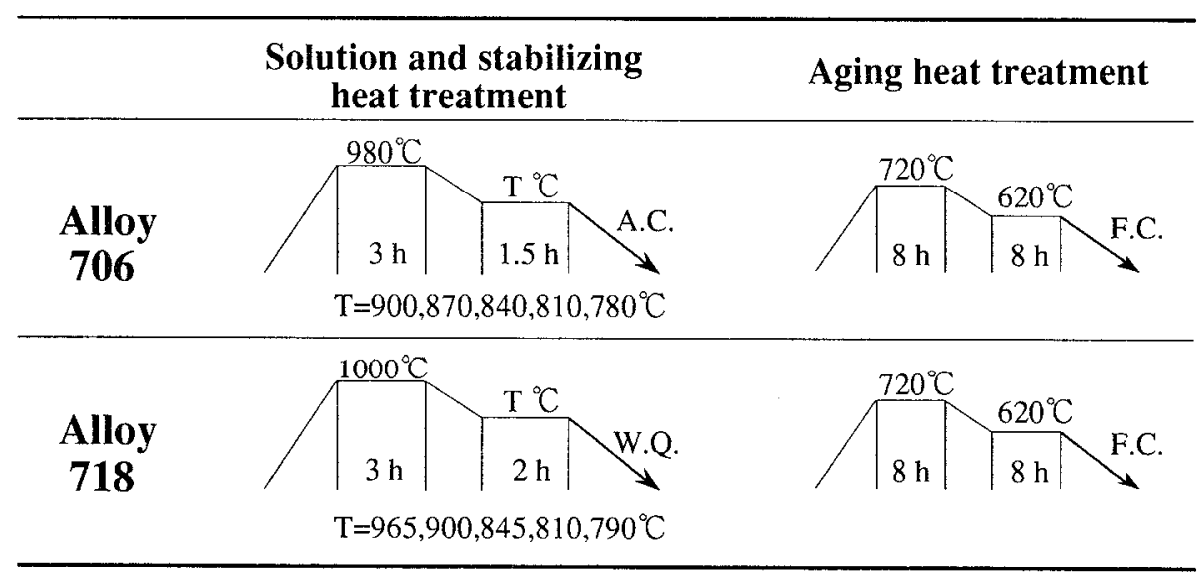

※ A.C. : Air cooling F.C. : Furnace cooling W.Q. : Water quenching

Figure 1 - Heat treatment conditions of Alloys 706 and 718 


\section{Results and Discussion}

\section{Short Term Tensile Properties}

Tensile test results for Alloys 706 from the specimens stabilizing heat treated at various temperatures are illustrated in Figure 2. In the figure, results without the final two-step age hardening are also presented in order to show the extent of age-hardening in the stabilizing treatment. Before the two-step aging treatment, $0.2 \%$ yield strength (Y.S.) and tensile strength (T.S.) for the materials stabilized at 840,870 and $900^{\circ} \mathrm{C}$ were in the same level as those of the solution annealed and unstabilized material. Increases in $0.2 \%$ Y.S. and T.S. were observed for the material stabilized at and below $810^{\circ} \mathrm{C}$. Though variations in T.S. and $0.2 \%$ Y.S. were not found at temperatures between 840 and $900^{\circ} \mathrm{C}$, remarkable decreases in reduction of area (R.A.) and elongation (El.) were observed as the stabilizing temperature was lowered. After the two-step aging, T.S. and $0.2 \%$ Y.S. slightly increased as the stabilizing temperature was decreased, and El. and R.A. gradually decreased at the same time, especially in the region between 870 and $840{ }^{\circ} \mathrm{C}$.

Change in tensile properties of heat treated Alloy 718 with stabilizing temperature are shown in Figure 3 . The distinctive changes for material strength and ductility are not observed in a stabilizing temperature range between 845 and $965^{\circ} \mathrm{C}$ as compared with the unstabilized material. However, $0.2 \%$ Y.S. and R.A. for the materials stabilized at 790 and $810{ }^{\circ} \mathrm{C}$ clearly decreased, conversely a little increasing tendency is observed in T.S.

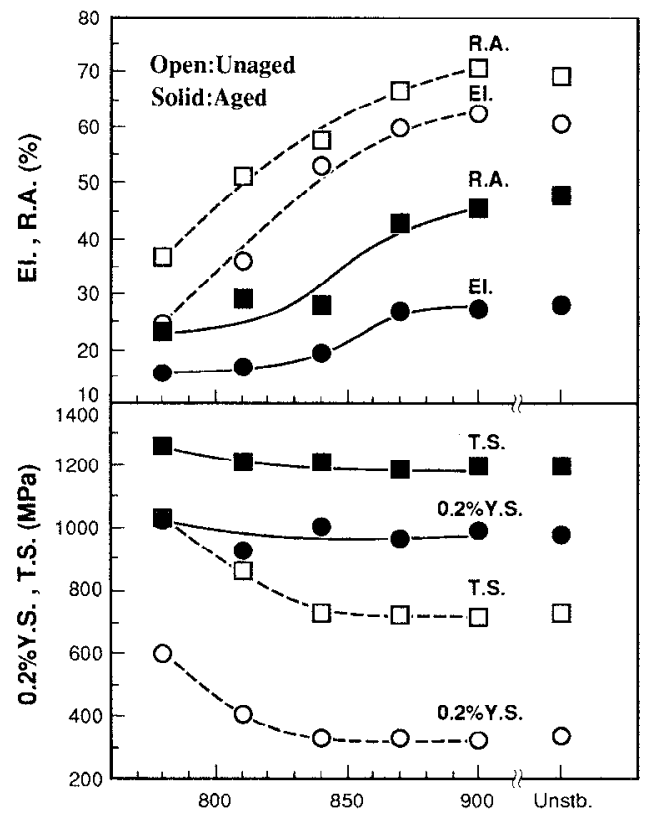

Stabilizing treatment temperature $\left({ }^{\circ} \mathrm{C}\right)$

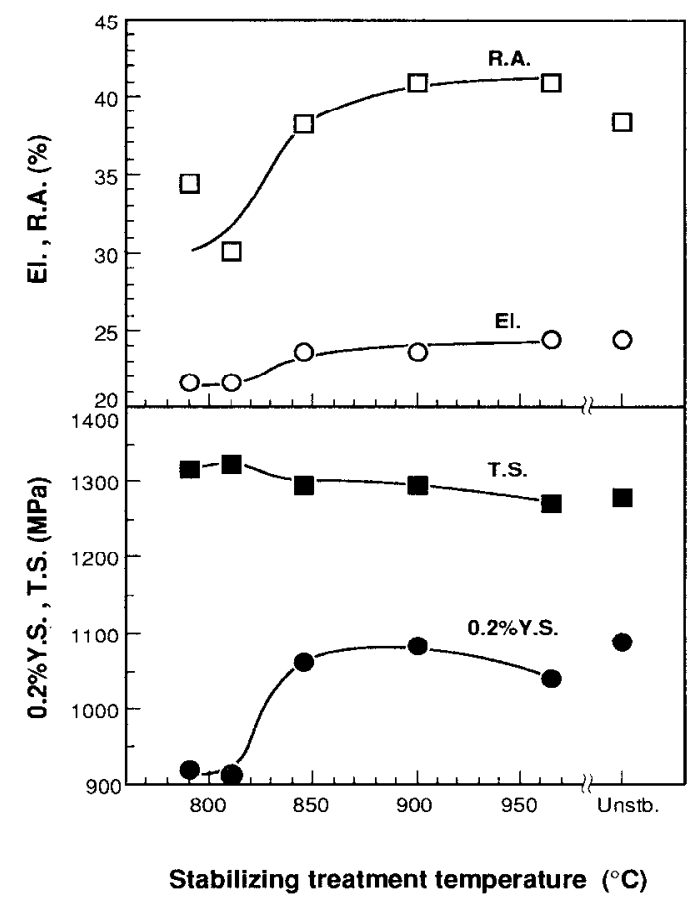

Figure 3 - Effects of stabilizing treatment temperature on tensile properties in Alloy 718 at R.T. 


\section{Secondary phase precipitations}

Optical microstructures in the grip portion of tensile specimens for aged Alloys 706 and 718 are shown in Figures 4 and 5, respectively. For Alloy 706, grain boundary precipitation began as the stabilizing temperature was lowered to $840{ }^{\circ} \mathrm{C}$, and the progress of excessive precipitation was observed in the of the material stabilized at $780^{\circ} \mathrm{C}$. Typical grain boundary microstructure of the stabilized Alloy 706 observed by TEM is shown Figure 6. These cellular precipitations at grain boundary were identified to be $\eta$ phase by electron diffraction analysis.

For alloy 718 , a uniform distribution of globular precipitates was observed in all the solution annealed and stabilized materials. The globular precipitates ware identified as $\delta$ phase by TEM observation. Besides, excessive precipitation was observed in the materials stabilized at and below $810^{\circ} \mathrm{C}$.

Based on these observations, it may be concluded that the critical stabilizing temperature for tensile ductility drops is related to the temperature for grain boundary precipitation during the stabilizing heat treatment. Especially in Alloy 706, ductility conspicuously decreases as the grain boundary precipitation of $\eta$ phase occurs by the stabilizing treatment at and below $840^{\circ} \mathrm{C}$.

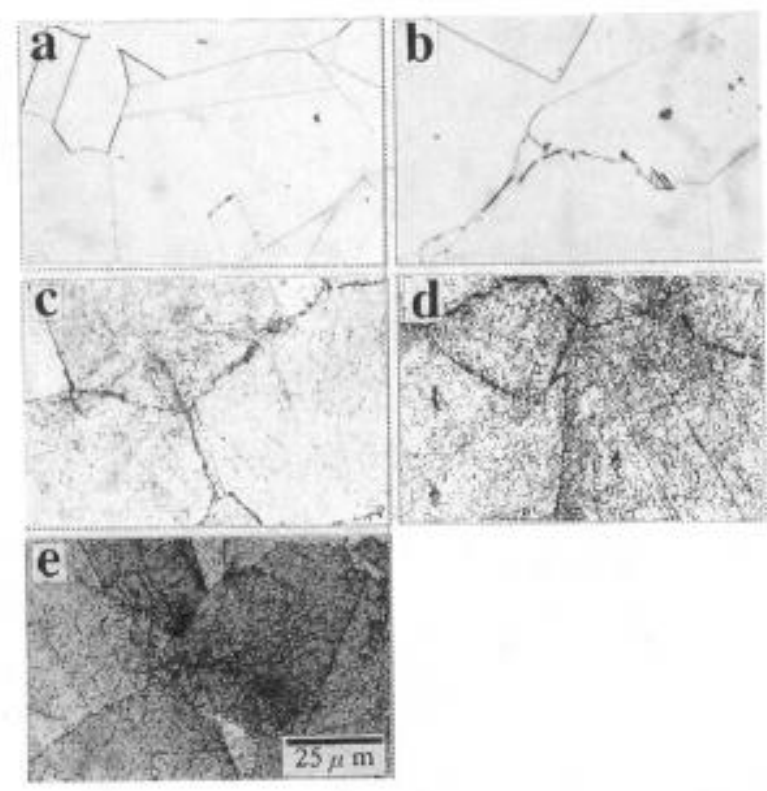

Figure 4 - Change in optical microstructure of alloy 706 with stabilizing temperature after solution heat treatment at $980^{\circ} \mathrm{C}$ for $3 \mathrm{~h}$.
a) $900^{\circ} \mathrm{C}$ for $1.5 \mathrm{~h}$
b) $870^{\circ} \mathrm{C}$ for $1.5 \mathrm{~h} \quad$ c) $840^{\circ} \mathrm{C}$ for $1.5 \mathrm{~h}$
d) $810^{\circ} \mathrm{C}$ for $1.5 \mathrm{~h}$
e) $780^{\circ} \mathrm{C}$ for $1.5 \mathrm{~h}$ 


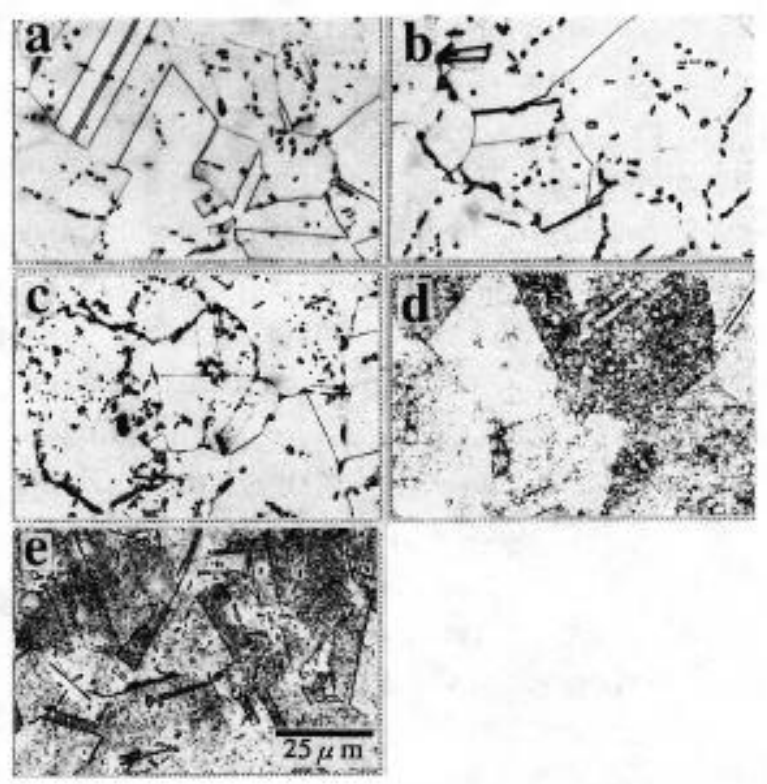

Figure 5 - Change in optical microstructure of alloy 718 with stabilizing temperature after solution heat treatment at $1000^{\circ} \mathrm{C}$ for $3 \mathrm{~h}$.

a) $965^{\circ} \mathrm{C}$ for $2 \mathrm{~h}$ b) $900^{\circ} \mathrm{C}$ for $2 \mathrm{~h}$ c) $840^{\circ} \mathrm{C}$ for $2 \mathrm{~h}$

d) $810^{\circ} \mathrm{C}$ for $2 \mathrm{~h}$ e) $790^{\circ} \mathrm{C}$ for $2 \mathrm{~h}$

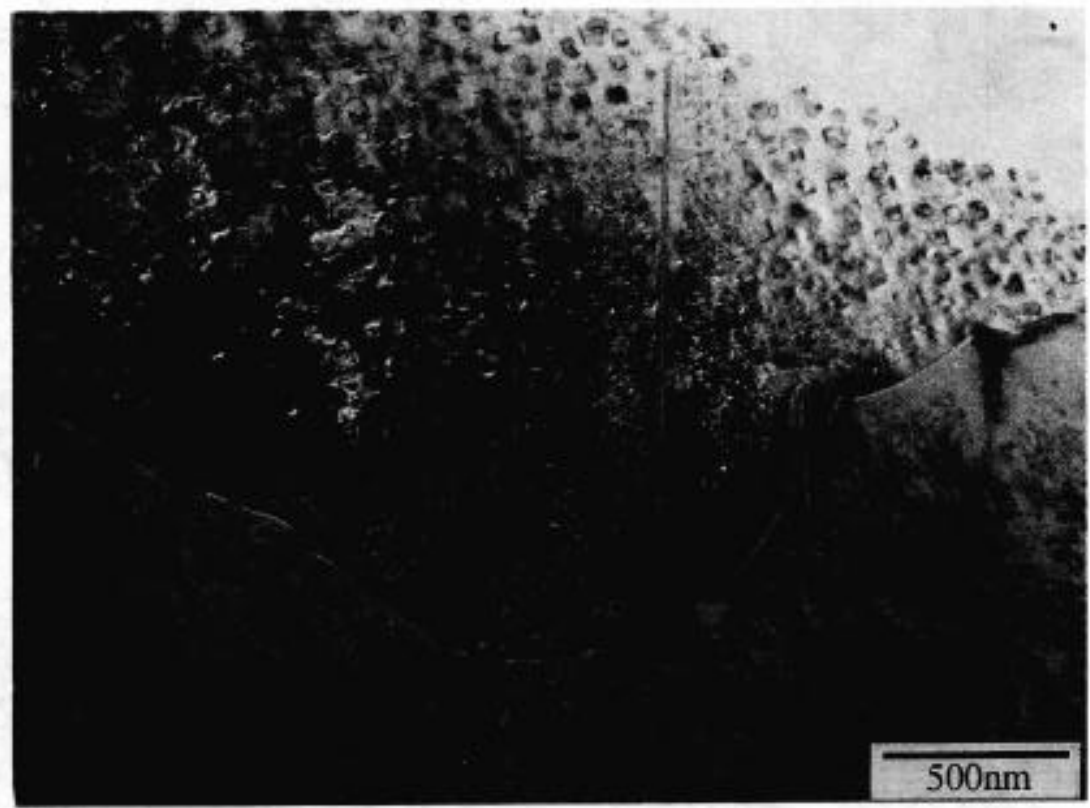

Figure 6 - TEM micrograph of Alloy 706 stabilized at $810^{\circ} \mathrm{C}$ for $1.5 \mathrm{~h}$ 


\section{Creep rupture properties}

In order to examine the effect of stabilizing heat treatment on the creep and creep rupture properties, creep strain vs. time curve of all the two-stcp aged materials were continuously measured at $600^{\circ} \mathrm{C}$ and applied stress of $745.3 \mathrm{MPa}$. The results are shown in Figures 7 and 8 . In the case of Alloy 706(Figure 7), relatively high stabilizing temperatures of $870^{\circ} \mathrm{C}$ and over did not appear to affect the creep properties. However, marked effects of the stabilizing treatment were found at $840^{\circ} \mathrm{C}$ and lower temperatures, where grain boundary precipitates of $\eta$ phase were expected to be formed. Sufficient rupture life and ductility were attained for the alloy stabilized at $810^{\circ} \mathrm{C}$. The improve rupture life is considered to be derived from the increased rupture ductility, because the steady state crecp strain rate staycd almost constant for all the stabilizing temperatures except $780^{\circ} \mathrm{C}$. Considerable decrease in the rupture life in Alloy 706 stabilized at $780^{\circ} \mathrm{C}$ is caused by over-aging during the stabilizing treatment.

Distinctive difference in creep properties was not observed for stabilized Alloy 718 in a temperature range between $845^{\circ} \mathrm{C}$ and $969^{\circ} \mathrm{C}$ as compared with the unstabilized materials. As the stabilizing temperature was decreased below $845^{\circ} \mathrm{C}$, the creep rupture life rapidly decreased in Alloy 718. Thus, the stabilizing heat treatment does not play any beneficial role on creep rupture properties of Alloy 718.

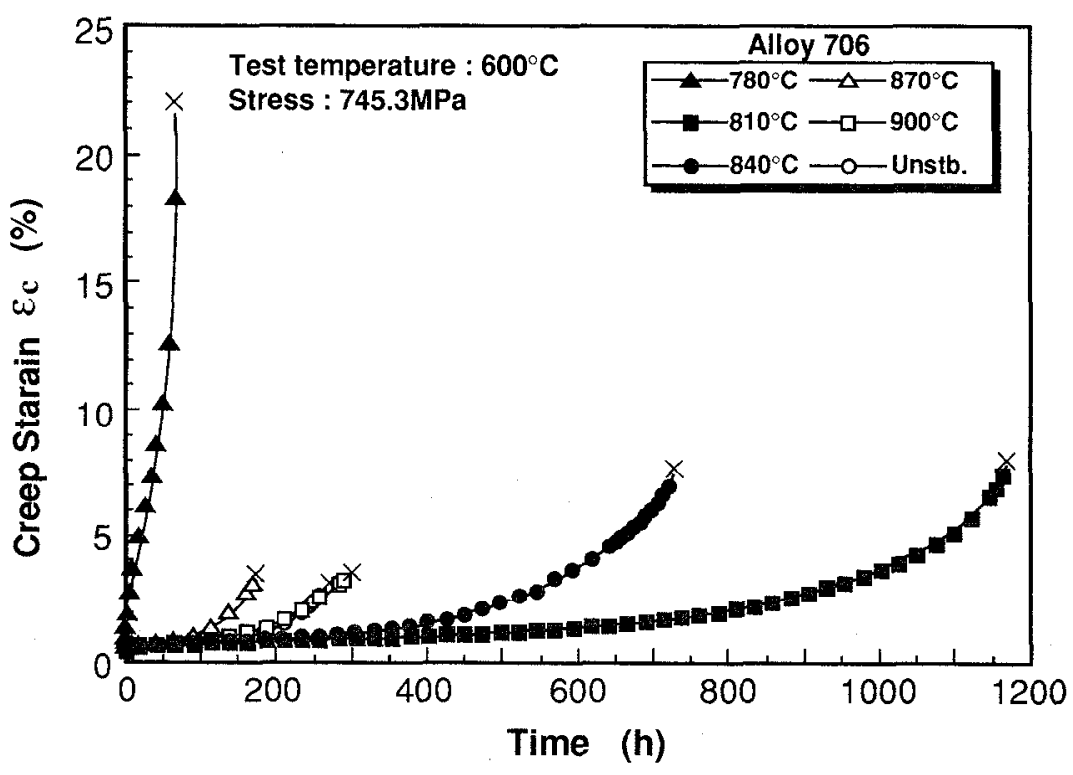

Figure 7 - Creep rupture properties of stabilized and aged Alloy 706 


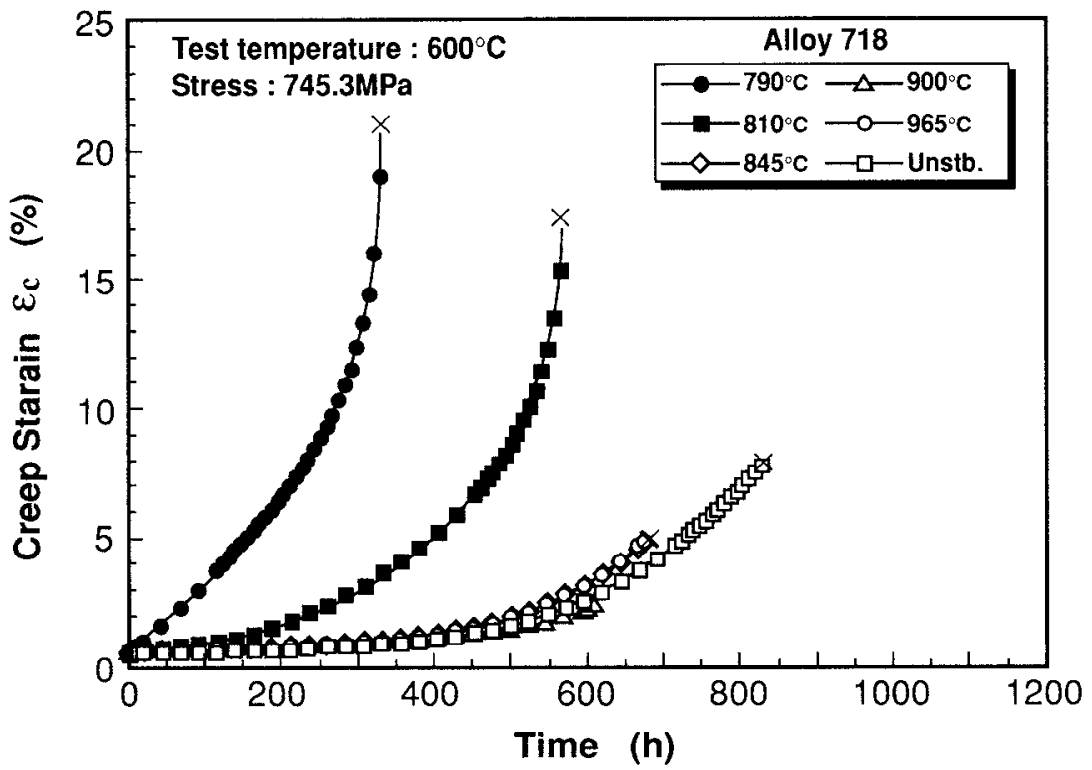

Figure 8 - Creep rupture properties of stabilized and aged Alloy 718

\section{SEM Fractgraphic Observation}

After the creep rupture test, rupture surfaces of the broken specimens were subjected to SEM fractographic observations. Typical grain boundary microstructure and corresponding rupture surface observed in Alloys 706 and 718 are illustrated in Figures 9 and 10, respectively. All of rupture specimens were confirmed to be broken in intergranular cracking mode. In the case of solution-Annealed and age-hardened condition without the stabilizing, creep rupture surface exhibited smooth appearance of grain boundaries and no signs of grain boundary precipitation. In contrast with this, creep rupture surfaces observed in the stabilized and aged Alloys 706 and 718 specimens showed high density of micro-dimples along grain boundaries. These grain-boundary dimples are considered to be originated by creep void formation at grain boundary precipitates such as $\eta$ and $\delta$ phase. It is implied that the grain boundary precipitates observed in the stabilized Alloy 706 contribute to prevention of grain boundary sliding by the pinning mechanism, which results in the improved rupture ductility and the rupture life.

As shown Figures 9(c) and 10(c), the morphology of grain boundary precipitates of the stabilized materials different between Alloys 706 and 718 . These needle shape and cellular precipitates in the stabilized Alloy 706 appeared to nucleate at a grain boundary and grow in specific intragrain directions, which resulted in the wavy shape of grain boundaries. Formation of the wavy grain boundaries is also considered to have relax the creep strain concentration at the grain boundaries. In the case of stabilized Alloy 718, grain boundary precipitation of $\delta$ phase also improved the creep rupture ductility as shown Figure 8 . However, the stabilizing heat treatment for Alloy 718 is considered to decrease the creep strength, which resulting in the increased steady-state creep rate. 

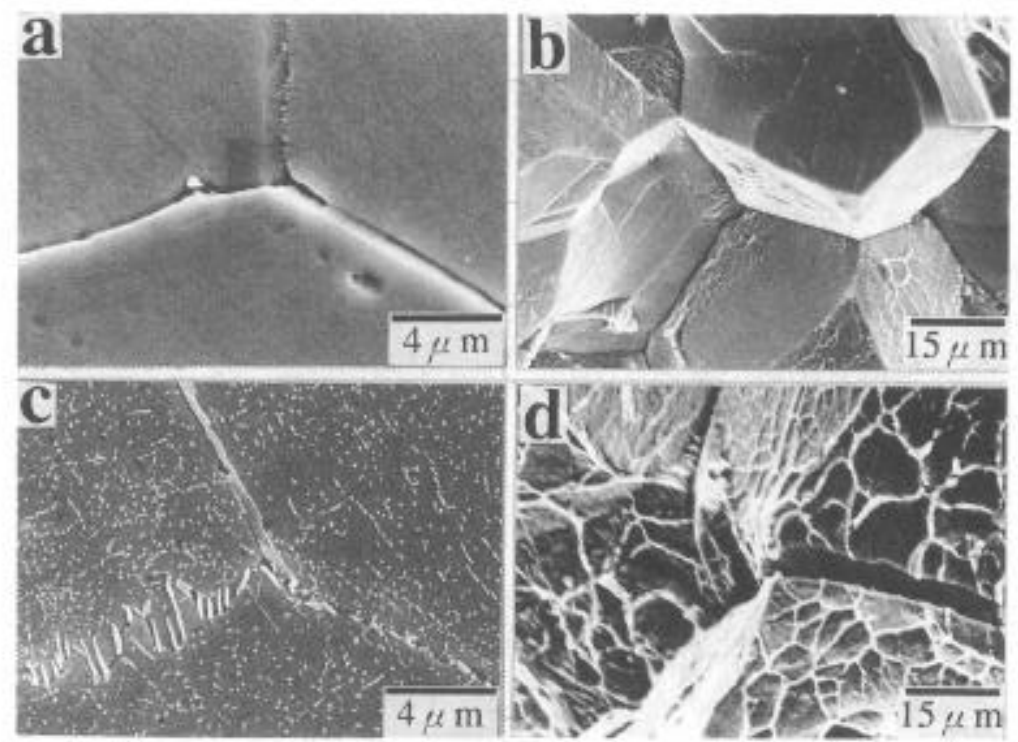

Figure 9 - SEM micrographs of grain boundary microstructure and creep rupture surface for Alloy 706
a), b) Unstabilized
c), d) $810^{\circ} \mathrm{C}$ for $1.5 \mathrm{~h}$
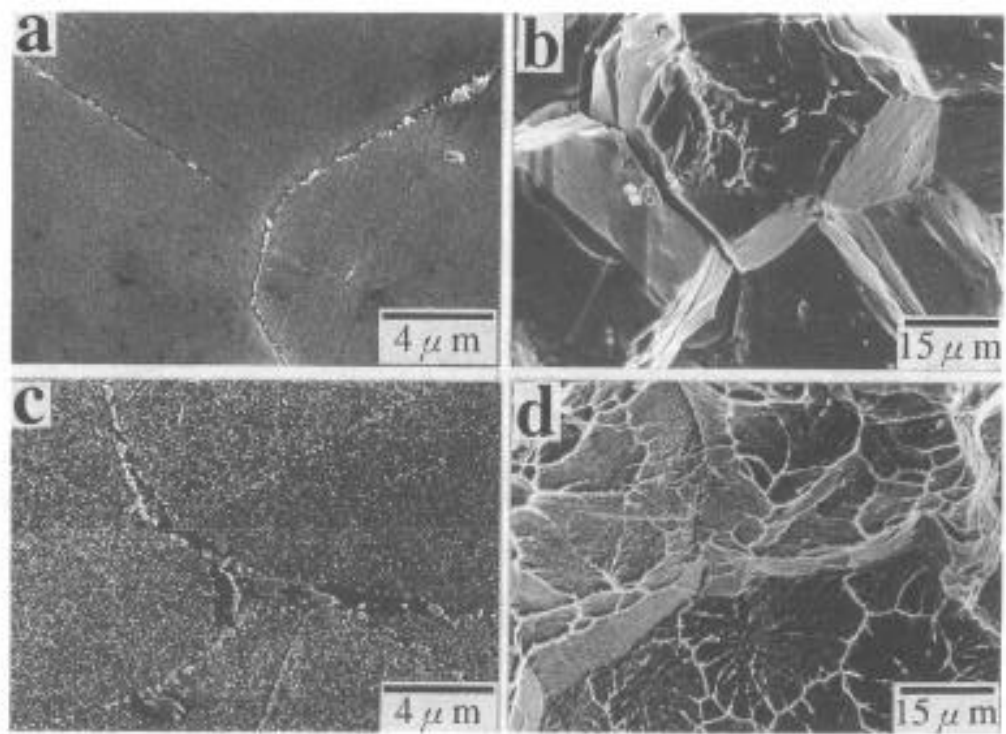

Figure 10 - SEM micrographs of grain boundary microstructure and creep rupture surface for Alloy 718
a), b) Unstabilized
c), d) $790^{\circ} \mathrm{C}$ for $2 \mathrm{~h}$ 


\section{Summary}

Morphology of the precipitates and shape of the grain boundary of Alloys 706 and 718 were intentionally varied by changing the stabilizing temperature between 780 and $900^{\circ} \mathrm{C}$. Significant improvements of the rupture life and ductility were found in the wavy grain boundary microstructures of stabilized alloy 706 with needle shaped and cellular precipitations of $\eta$ phase. These precipitates appear to originate at a grain boundary and to grow in specific intragrain directions, which result in wavy shapes of grain boundary. In contrast with this, straight grain boundaries with globular and plate-like precipitate were observed in the slabilized alloy 718 , which always caused the decreasing of creep rate and rupture life. It may be concluded that the beneficial effect of stabilizing treatment for alloy 706 is attributed to the wavy grain boundary formation and the dispersions of creep strain at these wavy boundaries.

\section{References}

1) H.L.Eiselstein, "Properties of a Fabricable, High Strength Superalloy," Metals Engineering Quarterly, Nov. (1971) , 20-25

2) W.J.Boesch and H.B.Canada, "Precipitation Reactions and Stability of $\mathrm{Ni} 3 \mathrm{Cb}$ in Inconel Alloy 718," Journal of Metals, Oct. (1969), 34-38

3) Donald R. Muzyka, "Controlling Microstructures and Properties of Superalloys Via Use of Precipitated Phases," Metals Engineering Quarterly, Nov. (1971), 12-19

4) John H. Moll, Ganvant N. Maniar and Donald R. Muzyka,"The Microstructure of 706, a New Fe-Ni base Superalloy," Metallugical Transactions, 2 (1971) , 2143-2151

5) R.Cozar and A.Pineau, "Morphology of $\gamma$ ' and $\gamma$ " Precipitates and Thermal stability of Inconel 718 Type Alloys," Metallugical Transactions, 4 (1973), 47-59

6) Inconel 706, undated brochure obtained from The International Nickel Company, 1974

7) L.Rémy, J.Laniesse and H.Aubert, "Precipitation Behavior and Creep Rupture of 706 Type Alloys," Materials Science and Engineering, 38 (1979), 227-239

8) John H. Moll, Gunvant N. Maniar and Donald R. Muzyka, "Heat Treatment of 706 Alloy for Optimum $1200^{\circ} \mathrm{F}$ Stress-Rupture Properties," Metallugical Transactions, 2 (1971) ,21532160

9) R.F.Decker, "Strengthening Mechanisms in Nickel-Base Superalloys," Symp. SteelStrengthening Mechanisms, May (1969) , 147-170 